\title{
Study on the Teaching of Japanese Translation in Colleges and Universities based on the Theory of Multiple-system
}

\author{
Duan Hongfang, Chen Yingchao \\ Heilongjiang University of Technology, Heilongjiang, China
}

Keywords: multiple system Theory; College Japanese Translation; Teaching Research

\begin{abstract}
The teaching of Japanese translation in colleges and universities needs to guide the students according to their actual learning situation. In the process of teaching practice, it can be found that the students' cultural accumulation level is insufficient. In many translation teaching, it is necessary not only to convey the correct grammar and the concept of sentence pattern analysis to the students, but also to introduce the basic knowledge of Japanese culture and society to the students in the process of translation. Otherwise, it is easy to make mistakes in translation. In fact, this is a common phenomenon, which can be systematized by the use of multi-system theory in teaching, which is helpful for teachers to promote the progress of translation learning on the basis of improving students' cultural cognition.
\end{abstract}

\section{Introduction}

The theory of multiculturalism was first put forward in the field of literary translation. Due to the rich cultural images contained in literature, cross-language translators need to have the basic ability of cultural understanding in two languages if they want to translate them correctly. Therefore, in the study of students, this situation still exists. Teachers need to study the theory of cultural system and apply it to the teaching of students in light of their actual learning needs. The research on translation related teaching based on multiple systems theory can promote the cultivation of translation talents in Japanese language education in China, which needs to be paid more attention to. This paper probes into the application of multi-system translation theory in Japanese grammar course, and trains students' thinking of translation presupposition.

\section{The importance of the application of multi-system theory in Japanese translation teaching}

\subsection{The emergence of multi-system theory has changed the direction of Japanese translation studies}

The most outstanding contribution of the multiple systems theory in the Japanese translation field is to transform the translation from a static, source-language-text-oriented study to a systematic, comprehensive and target-language-text-oriented vertical and dynamic study. Zohar's theory of multiple systems originated from the functionalist system theory. Its emergence 
completely changed the previous translation and other related studies' idea that the human world is a collection of many unrelated factors. It regards language, culture and society as an interrelated organic whole, while the term "multiple systems" refers to a network of literary systems combined by literary system and non-literary system. Edwin Genzler emphasized that the theory of multiple systems marked a significant development in translation studies, and concluded the following advantages: 1. the study of literary works itself and the study of social, historical and cultural forces are carried out at the same time. 2. Zohar moved from studying a single text in isolation to studying translation in the cultural and literary system, which can only play its role in the system. 3. Non-normative definitions of equivalence and adequacy can vary according to the historical and cultural context of the text.

\subsection{The emergence of multi-system theory has changed the position of text translation in the whole field of translation studies.}

Before the emergence of the theory of multiple systems, literary translation had always been regarded as a marginal part of the field of translation studies. However, Zohar believes that in the pluralistic system of literature, literary translation works can be regarded as both marginal and central parts. The status of literary translation will directly affect translation practice. When literary translation is at the center of the literary pluralism system, the translated works will be closer to the original works, while when literary translation is at the edge, the differences between the translated works and the original works will be great.

\subsection{The emergence of multi-system theory has changed the position of translation as a discipline.}

The multi-system theory has changed the traditional idea that translation is only a transformation between two languages. It has analyzed and interpreted the subject of translation from a cultural point of view. It has thoroughly improved the cultural status of translation behavior and translated works at the ideological level, thereby enhancing the academic status of the subject of translation. The theory of multiple systems expounds the essence and role of translation, promotes translation to a higher level, combines it with humanistic factors such as culture, society, economy and history, and expands the subject to a broader field. As M. Baker commented, "The theory of multiple systems has made a remarkable and remarkable contribution to our understanding of the nature and role of translation."

In the teaching of Japanese in colleges and universities, most of the students are exposed to Japanese initially, so they lack a comprehensive understanding of Japanese culture, society and other factors. In the author teaching experience, many students choose to learn Japanese because of the influence of Japanese animation culture, which is only one aspect of Japanese culture. Under this guidance, a rich cultural cognitive system can be established so that we can gain something in the training of translation teaching and the practice in the future.

In the teaching of translation, teachers should not only analyze correctly the grammar and vocabulary, but also extract the cultural factors, which can be reflected in translation through cultural transformation. Therefore, students also need to be based on the teacher' teaching to form the basic meaning cognition of translation exercises and the cognition of cultural transformation ${ }^{[1]}$.

\section{The influence of multi-system theory on Japanese translation teaching practice}

As a founding theory of translation, the theory of multiple systems not only has a far-reaching impact on translation studies, but also plays an indispensable role in the teaching practice of 
translation specialty. As a discipline, Japanese translation has only a history of less than 20 years in China. Both master's and undergraduate translation majors are still in the exploratory stage. However, the theoretical guidance of translation teaching is more limited to the translation of two or more languages and text translation, and does not fully extend the vision to the cultural field. Introducing the theory of multiple systems into the teaching practice of Japanese translation specialty will help students better understand the influence of culture, history and humanities on translation strategies, translation skills and questioning styles, thus improving their professional level and the teaching level of translation discipline. In addition, the framework structure of multi-system theory is also worth learning and promoting in the teaching process. According to the theory of multi-system, many systems have different behaviors, but they are interdependent. As an organized and holistic operation concept, translation courses can be divided into several organic systems, such as source language, target language, culture, history, translation strategies and translation choices, and a complete multi-system can be formed, which can help students learn translation from a higher and more comprehensive perspective. The professional knowledge of translation can also avoid the malpractice of focusing on words, words and sentences while ignoring discourse teaching in Japanese and translation teaching.

Although the theory of multiple systems has made outstanding contributions to modern Japanese translation studies and translation teaching practice, it still has many defects and shortcomings. As a guiding theory, the theory of multi-system itself is not perfect, and there are still many areas needing further improvement and research in its theoretical framework and details. Monabek once pointed out that the theory of multiple systems put forward by Zohar and other scholars is not a complete and perfect system, but more like the beginning of a long journey. From the perspective of translation, there are still many parts that have not been considered and involved in the theory of multisystem. Firstly, the theory is not only concerned with the field of translation, but also with the broader research fields such as culture and literature, which belongs to the theoretical study of culture. Zohar himself is more regarded as a cultural theorist than a pure translation theorist. Secondly, the theory of multiple systems only analyses the objective factors that can affect translation, such as cultural and literary factors, and puts forward the view that the status of literary works will affect translation strategies. However, it neglects the influence of subjective factors such as translators, readers and translation purposes on translation. In the course of his research, Zohar only pays attention to the objective cultural factors affecting translation strategies, but neglects the translator's subjective initiative as the subject of translation. Genzler once summarized the criticism of the theory of multisystem in the academic circles: "Firstly, the theory of multisystem overgeneralizes the general rules of translation based on the evidence of relative professors. Secondly, Zohar relied too much on the model of formalism in the 1920s, and according to his own evolution trend model, the model of formalism may not be suitable for the translation texts in the 1970s. In addition, Zohar tends to focus too much on abstract patterns, while ignoring the real life of the text and the translator. Finally, there is much controversy over the extent to which the scientific model proposed by the theory of multiple systems is truly objective.

The theory of multiple systems has led translation studies to the path of cultural studies. Traditional translation theories focus on static semantic comparison, often focusing on linguistic patterns or underdeveloped literary theories, while the pluralistic system expands the theoretical boundaries of translation studies and opens the way for translation studies to finally break out of the prescribed aesthetic limitations. However, some scholars have pointed out that the theory of multiple systems neglects the subjective initiative of the translator as the subject of translation. According to the theory of multiple systems, "the principle of choosing translated texts is determined by the situation that plays a dominant role in the multiple systems: that is, the texts are chosen because they are consistent with the new methods of target literature, and also because of 
their possible innovative role in target literature." However, the choice of the intended text is not only determined by a pluralistic system, but also by the translator's subjectivity.

\section{The Strategy of applying multi-system theory to Japanese translation teaching}

\subsection{Expanding students' cultural cognitive vision}

Due to the lack of language environment and social environment in the process of foreign language learning, the level of cognition and feelings of Japanese culture are relatively low. In the process of teaching, teachers face the situation of students and must make efforts in the spread of comprehensive culture in Japanese society. The process of translation is not a simple translation of two languages. In the process of translation, translators need to be able to make use of their own cultural understanding, perception, and the content of translation from the language and cultural transformation.

\subsection{Attaching importance to the cultural similarities and differences in east asian cultural circle}

Both China and Japan belong to the East Asian Cultural Circle and are important components of East Asian culture. Among them, the Japanese culture is deeply influenced by the Chinese culture, and there are many similar contents. The application of the pluralistic system theory in teaching can effectively promote students' cognitive content through the existing Chinese culture. Indirectly feel the composition of Japanese culture. At the same time, there are some differences between the two cultures, which constitute a special problem for Chinese learners based on Chinese language. For example, many Japanese words are expressed in Chinese characters, such as "toilet paper", "hutai" and so on, which are very different from the actual meaning in Japanese from the Chinese perspective. Therefore, in the process of learning, teachers need to make teaching comparison according to these different meanings to help students to establish a clear distinction. In addition, in the field of cultural history, there are also such characteristics, such as the warring States period in China and Japan, the Southern and Northern dynasties, and so on. Teachers are required to guide students to distinguish from a cultural point of view ${ }^{[2]}$.

\subsection{Apply multiculturalism to stimulate students’ interest in learning}

In fact, the learning process of language is more difficult. After a period of time, many students often feel the learning boring, the initial learning motivation is difficult to support their continued learning. In the teaching of translation courses, teachers need to guide students to explore Japanese culture, society and other realistic factors by using the theory of multiple systems. On the basis of this, the students’ new learning interest points are stimulated.

\subsection{Attach importance to the selection and compilation of textbooks}

The current Japanese translation textbooks are already very systematic in terms of translation theory system and facilitate the understanding of basic translation theories. However, the content is mostly confined to the translation of literary works, and the content is relatively old, which is divorced from the students' actual level. It is difficult to arouse students' interest in translation teaching by adopting authoritative Japanese translation textbooks at home and abroad to strengthen the guidance of translation theory and translation skills, and at the same time compiling their own teaching materials for interpretation and translation. The latest technical information and cultural 
information are incorporated in the handout to stimulate students' interest in learning and improve their translation practice ability ${ }^{[3]}$.

\section{Conclusion}

Multiple system theory provides a new cultural frame of reference for the study of various translation phenomena, and undoubtedly breaks through the old translation criteria. In the current teaching of Japanese translation, teachers should pay attention to the use of multicultural systems, guide students to correctly understand the different cultural conditions in language learning from a cultural point of view, and transform them into professional ways of translation. In order to enable students to have a higher degree of learning interest, teachers also need to apply cultural in-depth learning and inquiry as an opportunity to stimulate new learning motivation. At the same time, it is necessary to adjust the content of teaching materials in order to achieve a balance between teaching, teaching materials and students.

\section{Acknowledgements}

Heilongjiang province economic and social development key research project (foreign language discipline special item), the project name: Research on the practical study of foreign language translation teaching in colleges and universities under the thought of "Xin, Da, Ya" (subject number: WY2018037-B);

Source: project 2: Heilongjiang province economic and social development key research project (foreign language discipline special item), the project name: The research of the Japanese business translation based on the multi-system theory (project number: WY2018098-C).

\section{References}

[1] Zhao Lihong. On the Teaching of Japanese Translation in the Model of Applied Talent cultivation [J]. Journal of Hubei Institute of Science and Technology, 20144 N 34 (02): 185-186.

[2] Bai Zhengwen. Cultivation and Innovation of Japanese Translation Teaching ability [J]. Journal of Inner Mongolia University for nationalities, 2009-15 (03): 176-177.

[3] Zhang Suwen. On the infiltration of multiple systematic Translation Theory in Japanese Grammar Teaching [J]. Cong of Contemporary Teaching and Research, 2014 (04): 105. 